Psychopathology 1984;17(suppl. 1):1-3

\title{
Contents, Vol. 17, Supplement 1, 1984
}

\section{Contents}

Introduction 5

Changes in the Drug Treatment of Anxiety Disorders

Pohl, R.; Rainey, J.M., Jr.; Gershon, S. . . 6

Role of $\gamma$-Aminobutyric Acid in Anxiety

Enna, S.J

15

A Novel Chemically Induced Animal Model of Human Anxiety

Skolnick, P.; Ninan, P.; Insel, T.; Crawley, J.; Paul, S

Use of Animal Models: Toward Anxioselective Drugs

Eison,M.S 37

Benzodiazepine and Nonbenzodiazepine Anxiolytics

Goldberg, $\mathrm{H} \quad 45$

Relationship between Separation Anxiety and Panic and Agoraphobic Disorders

Gittelman, R.; Klein, D.F 56

Psychophysiological Factors in Panic Disorder

Freedman, R.R.; Ianni, P.; Ettedgui, E.; Pohl, R.; Rainey, J.M 66

A Comparison of Lactate and Isoproterenol Anxiety States

Rainey, J.M., Jr.; Pohl, R.B.; Williams, M.; Knitter, E.; Freedman, R.R.; Ettedgui, E

Avenues of Investigation for the Role of Catecholamines in Anxiety

Kopin, I.J

83

Mitral Valve Prolapse: A Marker for Anxiety or Overlapping Phenomenon?

B. Boudoulas

H.; King

B.D.; Wooley

C.F 98

CME Monograph Tests 